\title{
When Cultural Modifications are Taken into Account: Ibsen's A Doll's House on Iranian Screen
}

\author{
Hamideh Baggali B. \\ MA, Applied Linguistics, Azarbaijan Shahid Madani University, Tabriz-Iran \\ baggali.b.h@gmail.com \\ Mahdiyeh T. Khiabani \\ PhD Researcher, Ghent University, Ghent- Belgium \\ Mahdiyeh.tabaghchikhiabani@ugent.be
}

\section{Doi:10.5901/mjss.2015.v6n5s2p218}

\section{Abstract}

\begin{abstract}
How cross-cultural communications terminate in imperfect understanding can arguably be rendered by critical awareness about culturally differentiating conceptions in the interacting communities. This study aims to shed light on how an awakening message of a Western literary work can achieve a functional realization in an Eastern society via domestication of the cultural mnemonics. To this end, the present paper explored how Henrik Ibsen's A Doll's House was introduced to Persian culture as a movie entitled Sara by Dariush Mehrjui mediated by apprehending the intended function of the original work and cultural capital of the target community. Meticulous comparative analysis of A Doll's House and Sara yielded that the given successful 'transmission' was materialized through two levels of macro contextual and micro cultural domestications. Generic and thematic transformations at the former level and various strata of cultural turns at the latter have conceivably lent verisimilitude to Sara and its proximity to the cultural schema of Iranian audience, through which Nora in Norway could be 'translated' to Sara in Iran to enlighten both audience. It is hoped the arguments of this research can offer some critical points for both proponents and opponents of the debates on cultural turn in generic translation.
\end{abstract}

Keywords: cross-cultural communication, translation, cultural turn, domestication

\section{Introduction}

Since its first performance in 1879, A Doll's House has received a groundbreaking attention, highly valued by literary scholars for being among the first generation of "truly realistic plays in world drama" (Törnqvist, 1995, p. 1) and initiating a "break with idealistic esthetics" (Walker, 2014, p. 136). The play is a realistic observation of the status of women in the $19^{\text {th }}$ century family life of the time with respect to their deprived right of individuality, independence and, after all, selfrealization. The most significant characteristic of the play is its penetrating power; in fact, the play did not intend to call social attentions to the tragic status of women, but it was a harsh attack on women themselves and encouraged them to revolt against such history-long domestic enslavement, as Nora did against her marital identity.

Proving to be unbounded in space and time, the play soon gained a wide attraction all over Europe and even beyond its borders, in America. In half a century, it was even freshened by a change of medium from play to film. By 1978, twelve adaptations appeared, five of which were American (Törnqvist, 1995, p. 130). However, not all of these adaptations as either play or film were successful; one of the unsuccessful adaptations belonged to the British playwrights Arthur Jones and Henry Herman in 1884. They gave the original text a radical change for what they called "British theatrical taste" (Shepherd-barr, 1997, p. 23) in which they depicted a happy-ending. Törnqvist rightly argues this naïve adaptation created a parodic effect, and, by no means, could convey the message.

Having already launched its influence and fans in both Europe and America, the play paved its way to East by the Iranian director, Dariush Mehrjui, in 1992. Nevertheless, since the Islamic revolution of 1979, film productions are monitored by the Supreme Cultural Revolution Council (SCRC) and Ministry of Culture and Information Guidance (MCIG) - both "elaborate system[s] of councils to regulate and monitor every sphere of artistic expression" (Khorsandi 2006 11). Therefore, Mehrjui could not stick to the original text for two main reasons: first, a straightforward thematic and filmic translation of the original would fail to connect to the cultural expectations of the audience and thus needed a culturespecific, yet aesthetically appealing appropriation; second, due to the strict SCRC and MCIG monitoring of the films, 
suspicious of their broad appeal, the adaptation was forced to disguise the ideas of the original literary text in order to stand the test of restrictive control. In this way, the film managed not only to receive immediate attention by thousands of spectators, it also won many awards in national film festivals such as Fajr, and brought women into a "semi-centralized presence" in the cinema (Bahar 2010 144).

Mehrjui's loyalty to the original message hand in hand with its sophisticated appropriation to Iranian modern culture has been admired by critics like Wright (2003) and Naficy (2002; 2012). Sara owes its success and acceptability in Iranian society, the present study argues, to its natural domestication that resulted in the apprehension of the work as "Iranian self" than "the other Norwegian". Therefore, the aim of the present research is to investigate the cultural and Islamic modifications that could result in such a naturalized product without leaving single hint of "otherness" in the audience.

Sara, the Iranian film adaptation of A Doll's House, opens with Hessam's (Helmer in A Doll's House) illness getting worse and in urgent need of an operation in either Switzerland or Germany. Sara (Nora) is pregnant and her father is on his deathbed. She forges her father's signature and gets a loan from Goshtasb (Krogstad) who is depicted with more or less the same personality Ibsen describes Krogstad having had an affair with Sima (Christine), Sara's old friend. The narrative soon flashes forward to three years later; Hessam is promoted and their only daughter is three years old now. This coincides with Sima's return to Iran as a widow. Goshtasb is fired for which he has already started blackmailing Sara, and his position in the bank is offered to Sima. Having been disappointed by Sara, Goshtasb sends a mail to Hessam's office revealing the secret that Sara has forged her father's signature and has borrowed money from Goshtasb. Having read the letter from Goshtasb, Hessam harshly scolds Sara, accusing her of having an affair with Goshtasb. However, after Goshtasb returns the bond, he cools down and treats Sara as if nothing has happened between them. Now, it is Sara's turn to criticize Hessam and his coward reaction to her benevolent act of secretly sacrificing her youth in a dark room in the basement to make wedding dresses for a mason to be able to pay back the debt. Leaving Hessam in bewilderment, she abandons her husband to educate herself, first.

The key of success for Mehrjui's adaptation of a western literary work into an Eastern society is arguably for its two decisive orientations, a critical cultural appropriation in the process of cross-generic (play to film) translation of $A$ Doll's House to Sara and his functionalistic approach to this adaptation. The literature of translation studies in general and literary translation in particular has witnessed a process of transition from formalistic approaches towards extra-textual factors such as culture, context, history, and alike. It is widely known as the 'cultural turn' in translation, primarily associated with the works of Susan Bassnett, André Lefevere, and Lawrence Venuti.

It is argued that slavish linguistic loyalty, faithfulness or literal equivalence to the source text leaves a notorious track of exoticism and incomprehensibility to the target audience, whose critical reason was debated to lie in ignoring cultural issues inevitably interwoven in literary works. Bassnett and Lefevere (1990) write that "now the questions have changed, the object of study has been redefined, what is studied is the text, embedded within its network of both source and target cultural signs [italics added]" (p. 12). Accordingly, a translator neither encounters solely with a decontextualized passage, nor endeavors to find utterly literal equivalences, but s/he needs to deal with a kind of social composition with all its cultural and generic layers.

The aforementioned cultural awareness and appropriation are in service of the overarching function of the 'translation'. Advocated by movements like Skopos and descriptivism, what determines the employed strategies in the process of translation is the 'function' of translation. Skopos theory introduces translation as a goal-sensitive action tended for a functionalistic approach (Nord, 1997). When the utmost function of one translation is defined as the interaction between cultures, cultural factors are paid no less attention than that of linguistic and discoursal ones. Therefore, two notable characteristics of contemporary intellectual translation studies, namely a shift from source to target and the inclusion of cultural factors in alliance with linguistic elements (Gentzler, 2001), necessarily need to be invoked to meet the end. Lorna Hardwick (2000) metaphorically conceptualizes intercultural translation as transplanting into the cultural framework of the host language; it may imply that till this transplant is not successful, the translation operation cannot significantly function. Descriptivism, in the same vein, proposes the consideration of "who translates what, when, how, for whom, in what context, with what effect, and why?" (Hermans, 2007, p. 88).

Pragmatically wise, if a single translation action is to herald the awakening message of one literary creation in one culture into another culture with significantly different cultural maxims, the concepts of function, context and culture definitely cannot be neglected, and the act of translation without some attempts of cultural convergence of the source and target cultures would be an unsuccessful attempt. The rest of the paper explores the evident cultural turns leading to the successful 'translation' of Henrik Ibsen's Norwegian A Doll's House to Dariush Mehrjui's Iranian Sara. 


\section{Analytical Design}

To provide a deeper apprehension of how the cultural "rewriting of an original" (Bassnett, 2007, p. 14) has taken place in Mehrjui's Sara (1992) in order to transfer the enlightening message of Ibsen's A Doll's House from Norwegian society to Iranian screen, we meticulously analyzed the culturally significant constituents of the original text and the adaptation with a comparative orientation. The analysis equipped us with a thick corpus of field notes and memos whose grouping yielded two main categories of macro-level contextual rewriting and micro-level cultural rewriting. At the macro-level the medium of communicating with the addressees was completely changed cross-generically from play to film, and the overall presentation of the protagonist, Sara, was, to some extent, modified in comparison to Nora. The rationale behind these macro adaptations will be discussed in detail in the following section. Nevertheless, at micro-level, the adaptation illustrated the removal of the exoticism of the original work and "making the unfamiliar accessible through a set of strategies that enable the reader to travel vicariously guided by the familiar" (Bassnett, 2007, p.22), which yielded to be categorically discussed under Peter Newmark's adapted categorization of cultural translation. Newmark is one of the pioneers of highlighting cultural awareness in inter-cultural communications especially via the medium of translation.

Newmark (1988), first distinguishes two main translation procedures of 'transference' and 'componential analysis', where the former indicates more faithfulness to the source language (SL) culture, the latter takes the message as a priority and develops the proper means of translating it into the target language $(\mathrm{TL})$ culture with less concern to the SL.

Newmark calls the componential analysis "the most accurate translation procedure" (p. 96). He proposed five categories for "the translation of foreign cultural word" (95), namely, ecology, material culture, social culture, customs and concepts and gestures and habits. The five categories, in this study, are conceptualized as culturemes rather than sheer words. Ecology refers to geographical and spatial entities, such as hills and forests. However, in the present study, weather conditions and modern spatial changes such as architecture and interior design have also been included in this category and elaborated in the coming section. Material culture is comprised of materialistic entities like food, clothes, houses, towns that semiotically stand among the cultural and national elements. Social culture includes common social, occupational, family or leisure norms of every society. Costumes and concepts include religious, political, artistic or administrative customs and behaviors. Finally, gestures and habits deal with the facial expressions, body movements, and habitual behavior of the involved people. To properly transmit the entities from SL to TL, the cultural filter of the TL and the role of Translator (scriptwriter in the current study) as a mediator are believed to be crucially influential factors (Katan, 2009). The following section expounds the two folded culturally motivated macro-rewriting and microdomestication.

\section{Discussion}

\subsection{Macro-level Contextual Rewriting}

Macro-level rewriting was reveled in two main orientations, an inter-generic turn and a thematic priority turn. The first and foremost deviance from the original work was the change of medium from stage to cinematic presentation that requires a deeper consideration than taking it as a matter of a personal taste. Overall, there are different and sometimes contradictory views to the change of medium from stage to film. Schanke for instance, approves of the change Per Sjöstrand took in his Swedish film of the play in 1973, admitting that the medium moved beyond "the theatrical time/space continuum" and successfully highlighted the tension by the variety of locations (Törnqvist, 1995, p. 132). Törnqvist, on the other hand, criticizes Joseph Losey's French-English film version in which the change of medium, he asserts, is in conflict with the unity of the setting Ibsen meant to indicate. He writes the very fact that Nora leaves the doll house only once strengthens the feeling of the audience that she is really a prisoner in that house, which was violated by Nora's several outdoor exhibition in Losey's film.

Respecting Sara, the change of the presentation medium from stage to screen proves to be effective for two reasons; first, the priority of cinema to theatre in the technological context of $90 \mathrm{~s}$, and second, the cultural consideration of Iranian theatrical background that hand in hand puts stage secondary to film in Iranian culture. When Mehrjui produced Sara, media had already made a remarkable progress getting more available for the public. The tendency for cinemagoing was at its height while theatre was bitterly descending. Although the history of theatre in Iran goes back to centuries 
$\mathrm{ago}^{1}$, it has long been associated with heroic, mythical or religious themes ${ }^{2}$. After the Islamic conquest of the country, it served religious retellings and symbolic representations of the Islamic history ${ }^{3}$. On the whole, theatre, in its modern concept, has been repeatedly removed and re-launched in different stages of the country's political history. This has turned drama into an unstable and fragile art in the culture, and consequently not powerful enough to communicate the revolutionary ideas behind the works like $A$ Doll's House.

Besides, the inevitable alterations resulting from the change of medium including outdoor episodes, and removing soliloquies already experienced in the previous film versions, Mehrjui's Sara displayed another purposeful modification in relation to the main character. Sara is not as passive and dependent as Nora is. Sara is one of the characters on Iranian screen that depicts an alternative image about womanhood in contrast the common conceptualization of women as passive characters (Breese, 2011).

When the film starts, Sara appears smoking a cigarette, though in secret, that is incomparable to the macaroons Nora has whenever she has the opportunity. Sara later goes to the hospital, rushing up and down the stairs doing the official procedure while she is almost terribly pale under the heavy pressure of pregnancy. More importantly, unlike her overall childish diction when she talks to her husband, Sara repeatedly takes serious tone throughout the film that hints at her already, albeit hidden, constructed self in comparison to Nora. The other more significant factor that indicates more independence in Sara is the very fact that although she saves part of the money she receives from Hessam, the main source of her savings comes not from that budget but the domestic business she herself has created. In this sense, Sara is not as doll-like as Nora is. Having into consideration all these personal qualities and the final revelation of the couple on how men and women define each other, the message of Sara seems to shatter Iranian women about the sacrifice they have always done to men and family threshold in Iranian culture. In other words, Sara highlights the theme of unequal devotion while A Doll's house aims at self-realization. Sara was an avant-garde in Iran's cinema to depict such unequal attitude men and women have towards their marital life.

The final dialogue between Hessam and Sara seems more likely to carry the theme of unequal devotion. When Sara, shouting hysterically at Hessam's reaction to her forgery, accuses him to be coward, she speaks her mind and says she presupposed him to stand in front of Goshtasb, as brave as a man, and shut him up with saying that he would back her, and in case of being called to the court, he would get all the responsibility on his shoulders and save his wife, who had already saved him. Here, Hessam says that a man provides everything for his family and is delighted to do so, but he never sacrifices himself for women, love or family. Here Sara bitterly remarks that this is what women always do. The symbolic revelation Hessam makes was how men subordinately define women in the marital life. 'Putting self realization' in the background and having the 'unequal marital sacrifice' fore-grounded refers to one of the main elements of 'Iranialization' of the film. The context of Iran in 1992 would probably differ from the context of Norway in 1878, both in time and space. The Iranian film version appeared more than a century later, during which women's status had inevitably changed. If Nora were supposed to be recreated for a social movement in Norway a century later, it would have definitely required much more modifications. That Iranian women of 1992 were more independent with more active roles in domestic and social scenes would reasonably justify the change of the title from A Doll's House to Sara.

\subsection{Micro-level Cultural Rewriting}

This section aims to discuss how micro cultural grids in A Doll's House were domesticated in Sara according to the cultural horizon of Iranians, the discussion of which is to be presented on the premise of Newmarks' cultural translation categories.

\subsubsection{Ecology}

Setting and stage decoration highly matters in drama, specially for Ibsen's A Doll House where the locality of the living space symbolically stands for female imprisonment in family life (Shepherd-Barr, 1997, p. 22). The ecological analysis indicated, one, and very decisive, cultural modification of the building. Unlike the original setting, the building was given a

\footnotetext{
1 "Indigenous theatrical activities have existed in Iran for many centuries and have undoubtedly had an important role in the cultural life of the country. In his epic book Shahnameh (The Book of Kings) the Iranian Poet Ferdowsi notes that King Bahram Gur (AD 420-38) of the Sassanian Empire ordered the importation of ten thousands musicians and performers from India to Iran" (Lazgee 1).

${ }^{2}$ For more on the role and effect of religious and particularly Islamic performance on the development of theatre in Iran, see Katherine Brisbane et al.

${ }^{3}$ Among the most popular types of religious theatrical performances, are Rowze khani (recitation of the threnody), Shabih (Simulation), and Ta'ziyeh (Mourning).
} 
big traditional yard, typical to Iranian houses in the 90s that gave the film a touch of gothic atmosphere resulting from the weariness of the yard walls and aged trees. Regarding the interior design, Ibsen's description of the stage describes the house as "a pleasantly and tastefully, but not expensively furnished living-room", which gave the place a touch of warmness. The given description and its subsequent impressions were removed from the Iranian version, which should be looked upon from an Iranian cultural perspective. Ibsen's message in the play was "freedom and independence" (Sprinchorn, 1965, p. 179); For Iranian minds, 'pleasant and tasteful' furnishing is an indicator of fortune; for them, no housewife can tastefully furnish a house unless they experience the taste in their marital life. And there is no single reason or rationale for an Iranian wife of 90 s to rebel against a tasty family life, and abandon the family in search of knowing her very self. The independence of such a wife, an Iranian mind of 90s would judge, does not cause such big concerns as far as happiness is preserved. To successfully communicate the domestically "enslaved" nature of Sara that requires a firm will to reach freedom, Mehrjui has replaced the pleasant and tasteful setting of Nora's house with a gloomy, dark and weird building. Even the room that serves as Sara's sanctuary and free-land is a very gothic room in the basement with so many horrifying stairs down the building. The room includes one single window that is always blinded with curtains, and no little light can penetrate in. The adopted ecological modifications have been successful in communicating the prison Sara has stuck in from which she gravely needs to get out and search for a better life through growing an independent identity.

\subsubsection{Material Culture}

In each culture, typical materials such as domestic furniture, house decoration, common clothing and special costumes generally bear varying degrees of cultural connotations as a material culture proposed by Newmark. Although the crosscultural differences and cultural sensitivity of such materials may not be consciously felt by the people of the same community, in a comparative approach their semiotic significance reveals to act as cultural sensitive entities. With a zeal of removing exoticism and 'other cultureness' for an Iranian eye, on the pathway of $A$ Doll's House to Sara, , the cultural sensitive materials in A Doll's House were either neutralized or replaced by their Iranian counterparts (see Table 1).

Table 1. Domestication of Culturally Sensitive Materials in A Doll's House and Sara

\begin{tabular}{lll}
\hline A Doll's House & $\rightarrow$ & Sara \\
\hline Rocking chair & $\rightarrow$ & Wooden chairs \\
Piano & $\rightarrow$ & Bookcase \\
Wine & $\rightarrow$ & Juice \\
Cloak and hat & $\rightarrow$ & Chador \\
Italian costume & $\rightarrow$ & Iranian costume \\
Dancing dress & $\rightarrow$ & $\varnothing$ \\
Christmas tree & $\rightarrow$ & $\varnothing$ \\
\hline
\end{tabular}

As indicated in Table 1, a rocking chair usually depicts a foreign scene in an Iranian mind; conscious of its connotative meaning, it was replaced by traditional wooden chairs signifying traditional atmosphere of Sara's household and an attachment to Iranian ancestors. It depicts a middle-class family with traditionally established values, one of which can be the typical patriarchal family structure. In a similar fashion, the piano has been replaced with a bookcase in the Iranian version to provide the image of a traditional Iranian family of the $90 \mathrm{~s}$, due to the fact that playing musical instruments did not take part of middle-class hobbies at the time. Instead, the bookcase languishing on a corner of the house was and still is associated with common interior design of a middle-class family, which probably implies the zeal for learning and possibly foreshadowing Sara's final 'learning'.

The other two categories both bear cultural and religious connotations logically supposed to be modified in Sara in to particularly overlook the religious horizon of thinking in Iranian culture. Since alcohol is prohibited in Islamic doctrine and therefore socially discarded in Iran, juice has become a replacement. Cloak and hat, also, depict an outfit, primarily in this work, for 'leaving'. To replace this set with another significant feminine outfit with the same function, Chador (black veil), the usual Islamic cover for Iranian women especially in the $90 \mathrm{~s}$, sounds to be a right choice to connote both traditionalism and highly acceptable religious level of Sara's faith and social morality. Moreover, Italian costumes and dancing dresses were reshaped by neutral equivalents typical of Iranian clothing commonalities, and the Christmas tree was removed altogether since it was a mismatch for the context of Sara's home with an Islamic-Iranian culture. The ironic representation of Christmas party supposed to signify a happy time in contrast to the actual coming crisis in A Doll's 
House were transformed to Hessam's birthday party that Sara held, possibly to signify both the original irony and Sara's sincere dedication to her husband's happiness corresponding to Nora's dancing to satisfy Torvald.

The aforementioned adapted material alternatives, depicting a typical traditional and religious home in Iran at a visual level, were tactful choices in Sara in service of providing a naturalized and domestic cultural embedment for nourishing the intended message within the cultural maxims of Iranians. This is in line with the functionalistic point of view practiced in descriptivism and Skopos theory; translation is a goal-directed action (Nord, 1997) and the realization of the intended goal demands a fertile setting.

\subsubsection{Social Culture}

Cronin metaphorises translators as travelers getting engaged in dialogue with different languages and cultures and act as a nomad bringing the news from far lands, and since the two communication contexts are not parallel, this nomad should tell the story in the 'language' of her/his own people (Hermans, 2007). Table 2 depicts how A Doll's House was comprehensibly retold to Iranians via particular cultural maxims of Sara's people.

Table 2. Socio-cultural Turns from A Doll's House to Sara

\begin{tabular}{ll}
\hline A Doll's House & $\rightarrow$ Sara \\
\hline Macaroons & $\rightarrow$ Smoking \\
Krogstad visits Sara at home. & $\rightarrow$ Ghoshtasb visits Sara at bank or street or yard. \\
Dr. Rank & $\rightarrow$ Nobody \\
Leaving the children & $\rightarrow$ Old aunt \\
An old maid & $\rightarrow 1$ child \\
3 children & $\rightarrow$ Keeping the rings \\
Exchange of rings & $\rightarrow$ Hessam's birthday \\
Fancy-dress Ball & $\rightarrow$ Hessam dances traditionally \\
Nora dances & $\rightarrow$ Sima had two sisters. \\
Chistine had two brothers. & \\
Calling Nora by different titles like: & $\rightarrow$ Mylling Sara by two titles, namely: \\
My little squirrel & \\
My little featherhead & Poor helpless little creature \\
My sweet skylark &
\end{tabular}

In service of depicting Nora's covert defiance against her husband's value systems, buying macaroons in spite of Torvald's disagreement is used as a signifier in Ibsen's work. Indicating the same function, even much stronger, through an act of domestication, Mehrjui replaces it with Sara's smoking as a masculine habit in Iranian culture. As a sign of protesting against the defined social framework for women, smoking implies Sara's rebelliousness and foreshadows her decision to give priority to her husband's wellbeing over the law and committing a forgery to save a life and therefore a family.

Nora and Sara's high moral status, which Ibsen and Mehrjui intended to visualize, is a key point in their characterization that demands a high cultural familiarity with the connotative cultural-specific grids. While Nora was illustrating her high concerns of morality by avoiding asking for Dr. Rank's help after he had confessed loving Nora, the appreciation of Sara as a woman with high moral standards was culturally tuned to Iranian cultural capital; for instance, there is no such a person like Dr. Rank in Sara. A male family friend who comes to a friend's home when the husband is not at home is an unacceptable behavior in Iranian culture, which may bring the fidelity of the woman and the good intentions of that man under question. Accordingly, Dr. Rank's role was completely discarded in Sara due to its social and marital misconceptions. On the other hand, the sacredness of domestic privacy in each culture and society defines another factor in the family ethics. In Iranian culture, a male acquaintance is not ethically allowed to visit a woman alone inside the home, since it can bring scandals for both and mainly for the woman. For this reason, Sara and Goshtasb always meet outside the house in contrast to that of Nora and Krogsad. Accordingly, gender matters and related implications in various contexts can also integrate considerable degrees of cultural specificity.

The additional point relates to children in family bounds. The ethics of parental devotion to the well being of children may reasonably vary in different societies that can explain the difference between Sara and Nora's decision about their children at the time of leaving for self-discovering. Iranian unwritten ethical rule and motherly emotion have generally prescribed greater devotions for mothers than fathers. Being a highly responsible and emotional wife and 
mother, at the end of the film Sara did not leave her daughter alone and decided to take her with herself in contrast to Nora's decision leaving her children with Torvald.

Regarding the social commonalities and cultural-specificity in Iran, whenever a young couple is to coexist with elderly people, typically fathers, mothers or aunts would be the most common people; and for the same reason of naturalization, an elderly aunt in Sara played the role of the old maid in A Doll's House. Moreover, Nora's three children were reduced to only one child since having three children after a marital life of three years would be possibly presupposed as a matter of parental carelessness in Iranian society. In addition, to take an example related to cultural rituals in this work, exchanging the rings at the time of marriage is actualized in Iran through a public ceremony at least with the presence the couples' parents; therefore, the similar official procedure is expected for ending the marital life by the exchange of the rings. This was logically the rationale behind keeping the ring when Sara was leaving her home at the end of the film while Nora exchanged the rings in the same scene. Coming to the social gatherings, the fancy-dress Ball was modified by Hessam's birthday probably signifying Sara's attempt to do her best for satisfying Hessam as a dedicated wife. Moreover, as for the legal restrictions on the screen, the dancer of the movie was Hessam and not Sara. Furthermore, Sara's friend, Sima was taking care of her two sisters rather than two brothers by Nora's friend, Christine. It may be interesting to know that in the patriarchal society of Iran, it is usually brothers who take care of their sisters in troublesome situations even if they are so young and it is rarely the other way around; consequently, to signify Sima's obligation for taking care of her siblings, the gender modification seemed a necessity.

Linguistically speaking, in the social and cultural atmosphere of the 90s in Iran, men were generally too strict about addressing their wives with different titles and nicknames to show their tender feeling towards them, which was supposed to be a threat to their masculine power. The given culturally dominant belief was probably the main reason of using limited expressions instead of varying forms (see Table 2) in A Doll's House; however, 'little', as one significant component of them, was preserved due to the faithfulness to the subordinative connotation of the addressing expressions.

To sum up the significance of the aforementioned signifiers, the dominant cultural turns on the way of $A$ Doll's House to Sara were the modification of cultural sensitive issues such as social customs and commonsense, conformity and defiance symbols, common ethics and responsibility domains, and gender modification, without which "a hybrid space, a space in-between cultures" (Bassnett, 2007, p. 22) could not be established and the otherness and foreign sense of Sara would have disturbed the full attention of the Iranian audience and functional transmission of the message of the original work.

\subsubsection{Customs and Concepts}

In search of evident culturemes in the category of customs and concepts, characters' names, social events, and religious concepts yielded to be apparent different entities (See Table 3).

Table 3. Domestication of Culturally Sensitive Customs and Concepts in A Doll's House and Sara

\begin{tabular}{ll}
\hline A Doll's House & $\rightarrow$ Sara \\
\hline Nora/Torvald/ Krogstad/ Christine & $\rightarrow$ Sara/Hessam/ Goshtasb/ Sima \\
Lottery & $\rightarrow$ Nothing \\
Non-religious & $\rightarrow$ religious \\
\hline
\end{tabular}

One may admit that names are not sense-free concepts without connotative layers. In the process of domestication, not only the change of names is a necessity, but also their replacement with culturally appropriate equivalents cannot be pointless. In this study, Nora is replaced by Sara that is a stereotyped Iranian name generally associated with the characteristics of being timid, kind, devoted and religious. Hessam is a name generally associated with the middle or high class strata in Iranian society then. It could be an attempt to awaken Iranian audience about the severity of common patriarchal practices even in middle class families supposed to enjoy enlightened minds. Goshtasb resembles Krogstad both phonetically and connotatively. Phonetically, they have a similar sound composure, and connotatively, Goshtasb generally connotes a domination seeking, greedy and self-centered person in alliance with his role in Sara. Moreover, Sima which literary means facial complexion and appearance is likely to connote a person whose appearance may differ from her inner characteristics which puts her in line with the way she treated Goshtasb and Sara. These connotatively appropriate names can, consciously or unconsciously, leave a significant impact on the mental framework of the audience and internalizing the characters as one of themselves. Furthermore, apart from the given appropriation, omitting 
and inserting some cultural-specific elements can reinforce the power of cultural turn in translation. Accordingly, lottery was removed from the scenario, and religious concepts were instilled in Sara to logically naturalize the depiction of a typical Iranian family by a sort of deletion and naturalization named among the most frequent translation strategies (Munday, 2001). For instance, while A Doll's House does not seem to be a religious work, Islamic customs and concepts, like praying and Islamic discourse, are overtly evident in Sara. Therefore, appropriate selection of names and adding some necessary cultural flavor in service of the function of translation can enhance the acceptability of the cultural translation in the target culture.

\subsubsection{Gestures and Habits}

Body language and proximics can also play a role in the naturalization and domestication of a translated work. In the play, Nora usually tried to show her feminine enthusiasm towards her husband and her marital life, generally speaking, by gestures like outstretching her hands to receive a hug from or give a kiss to Torvald. However, due to the limitations regulated by SCRC and MCIG about screening private matters- physical touch between a man and a woman in this caseSara attempted to play the same function by great cooking for the family and keeping her house as tidy as possible. As the most dominant in the case of this work, Nora's affectionate physical acts towards her husband were simply compensated for with Sara's willingness to ideally prepare food and clean the house.

\section{Conclusion}

The present study aimed to provide a case study of adaptation based on Henrik Ibsen's A Doll's House adapted into an Iranian movie by one of the most famous directors in the contemporary Iranian cinema. The interest for such a case study was mainly initiated by the fundamental differences in the socio-cultural structure of the contexts in which the two works were produced. Besides such enormous differences, the ideological status of the target country was also one of the negotiable factors in the study of this adaptation. As the analysis indicated, the adaptation and appropriation tendencies have meticulously considered the ideological, social, cultural, as well as the temporal gap between the source work and the target work to the extent that the message has appropriately been transmitted to the film despite such differences. The breadth and depth of appropriation has resulted in a fully domesticated and socio-culturally meaningful adaptation that indicates the significant role of awareness in cross-cultural communication. Appropriate implementation of such adaptation strategies in service of the accommodation of a 'strange' work to the cultural maxims of the host community are of crucial importance for acceptability and functionality of the adapted work.

\section{References}

Bahar, M. (2010). Religious identity and mass media: The situation of women in Iranian cinema following the Islamic revolution. Journal of Media and Communication Studies, 2 (6), 144 - 153.

Bassnett, S. (2007). Culture and translation. In P. Kuhiwczak, \& K. Littau (Eds.), A companion to translation studies (pp. 13-23). New York: Multilingual Matters Ltd.

Bassnett, S., \& Lefevere, A. (Eds.). (1990). Translation, history and culture. London: Pinter.

Breese, B. (2011). Film literature of Middle Eastern women: Explorations from Egypt, Iran, and Turkey. Retrieved from http://www.tip. sas.upenn.edu/curriculum/units/2011/04/11.04.01.pdf

Gentzler, E. (2001). Contemporary translation theories. London: Routledge.

Hardwick, L. (2000). Translating words, translating cultures. London: Duckworth.

Hermans, T. (2007). Literary translation. In P. Kuhiwczak, \& K. Littau (Eds.), The companion to translation studies (pp. 77-91). North York: Multilingual Matters Ltd.

Katan, D. (2009). Translation as intercultural communication. In J. Munday (Ed.), Translation studies (pp. 74-92). New York: Rutledge.

Khorsandi, H. (2006). Unveiled: Art and censorship in Iran. London: Global Campaign for Free Expression.

Marinetti, C. (2011). Cultural approaches. In Y. Gambier, \& L. Doorslaer (Eds.), Handbook of Translation Studies (Vol. 2, pp. 26-30). Amsterdam: John Benjamins Publishing Company.

Munday, J. (2001). Introducing translation studies theories and applications. New York: Routledge.

Naficy, H. (2012). A social history of Iranian cinema: The globalizing era, 1984-2010. Durham: Duke University Press.

Naficy, H. (2002). Cinematic exchange relations: Iran and the West. In N. R. Keddie, \& R. Mathee (Eds.), Iran and the surrounding world: Interactions in culture and cultural politics (pp. 254-280). Washington: University of Washington Press.

Newmark, P. (1988). Approaches to translation. London: Prentice hall international (UK) Ltd.

Nord, C. (1997). Translating as a purposeful activity: Functionalist approaches explained. Manchester: St Jerome.

Törnqvist, E. (1995). Ibsen: A doll's house. Cambridge: Cambridge University Press. 
Shepherd-Barr, K (1997). Ibsen and early modernist theatre 1890-1900. Westport: Greenwood Press.

Sprinchorn, E. (Ed.). (1965). Ibsen letters and speeches. New York: Hill and Wang.

Walker, J.A. (2014). Suez modernism: transportation, history, and Ibsen's stylistic shift. Ibsen Studies, 14(2), 136-166.

Wright, R. (2003). Darius Mehrju'i's Sara: A Doll House through an Iranian lens. Ibsen Society of America. Retrieved from http://www. ibsensociety.liu.edu/conferencepapers/iraniandollhouse.pdf 